Pendas : Jurnal Ilmiah Pendidikan Dasar,

ISSN Cetak : 2477-2143 ISSN Online : 2548-6950

Volume III Nomor 2, Desember 2018

\title{
STRUKTUR NILAI LOKALITAS PAPAREGAN MADURA SEBUAH ALTERNATIF BUDAYA UNTUK SISWA SEKOLAH DASAR
}

\author{
Sama'1 \\ 1STKIP PGRI Sumenep \\ 1'sultansamak@stkippgrisumenep.ac.id \\ Debrine Stefany² \\ 2STKIP PGRI Sumenep \\ 2deste@stkipgrisumenep.ac.id
}

\begin{abstract}
Madurese people maintain the language and culture of Madura which serves as a symbol of pride, identity and as a means of communication. Madurese language as an oral discourse has a wide coverage area, on the other hand written literature and oral literature. Generally, the contents of paparegan in Sumenep Madura are merely biological but they contain clear values in them. Based on the formulation of the problem, the purpose of this study refers to the description of the paparegan structure used in the District of Bluto. Structure is the relationship between the constituent elements in the overall arrangement. Structural theory addresses two problems, namely ethical and aesthetic problems. The approach used is a qualitative approach. Data collection techniques are carried out in triangulation (combined), data analysis is inductive, and the results of qualitative research emphasize structure rather than assumptions. This study sought to obtain empirical data and conduct a study of paparegan structures in Bluto District. Sumenep. The findings in the field stated that there were 3 forms of paparegan that were preserved, namely Karmina, Talibun and Saloka. Karmina is called paparegan (pantun) lightning because it only consists of 2 rows that render a-a. Talibun is a long type of paparegan with a very abundant number of rows. As for Saloka is paparegan which consists of a number of concurrent stanzas connected if they are written, muted. Elementary School Students should properly study Paparegan culture which is rich in Madurese locality values for future educational purposes.
\end{abstract}

Keywords: locality, paparegan, culture, structure, ethics and aesthetics, elementary school

\section{ABSTRAK}

Masyarakat Madura merawat bahasa dan budaya Madura yang berfungsi sebagai lambang kebanggaan, identitas dan sebagai alat komunikasi. Bahasa Madura sebagai wacana lisan memiliki wilayah cakupan cukup luas, di sisi lain sastra tulis dan sastra lisan. Umumnya, isi paparegan di Sumenep Madura ini bersifat hayalan semata namun di dalamnya terkandung nilai-nilai yang jelas. Berdasarkan rumusan masalah, maka tujuan penelitian ini mengacu pada pendeskripsian struktur paparegan yang digunakan di Kecamatan Bluto. Struktur adalah hubungan antara unsur-unsur pembentuk dalam susunan keseluruhan. Teori struktur membahas dua masalah yaitu masalah etika dan estetika. Pendekatan yang digunakan adalah pendekatan kualitatif. Teknik pengumpulan data dilakukan secara triangulasi (gabungan), analisis data bersifat induktif, dan hasil penelitian 
Pendas : Jurnal Ilmiah Pendidikan Dasar,

kualitatif lebih menekankan struktur dari pada asumsi-asumsi. Penelitian ini berusaha memperoleh data empiris dan melakukan kajian tentang struktur paparegan di Kecamatan Bluto Kab. Sumenep. Temuan di lapangan menyebutkan, ada 3 bentuk paparegan yang tetap dilestarikan yaitu Karmina, Talibun dan Saloka. Karmina disebut paparegan (pantun) kilat karena hanya terdiri 2 baris yang bersajak a-a. Talibun merupakan jenis paparegan yang panjang dengan jumlah baris yang sangat melimpah. Adapun Saloka adalah paparegan yang terdiri atas beberapa bait sambung-menyambung jika dilisankan, bersahutsahutan. Siswa Sekolah Dasar sudah sepantasnya belajar budaya Paparegan yang kaya akan nilai-nilai lokalitas ke-Madura-an untuk tujuan pendidikan masa depan.

Kata kunci : lokalitas, paparegan, budaya, struktur, etika dan estetika, sekolah dasar.

\section{A. Pendahuluan}

Madura merupakan salah satu pulau di Indonesia yang memiiki keanekaragaman yang sangat melimpah. pulau yang terdiri dari empat kabupaten tersebut memiliki beberapa kabupaten yang notabene masyarakatnya di setiap daerah memiliki keanekaragaman sosial, budaya dan kebudayaan masingmasing, contohnya masyarakat kabupaten Sumenep yang memiliki kebudayaan yang banyak sekali. Contohnya seperti Kerapan Sape, tari mowang Sangkal, Topeng Marlena, Ludruk, Tandha', Pencak silat Pamor, pencak silat Cimande dan lain-lain.

Keanekaragaman budaya dan sosial masyarakat sumenep tersebar di berbagai wilayah dengan karakteristik dan jenis tersendiri. Diantaranya adalah Kecamatan Bluto yang dikenal dengan Desa yang paling banyak memiliki kebudayaan dari pada beberapa kecamatan yang lain yang ada di Kabupaten Sumenep. Kebudayaan yang dimaksud adalah seperti Kerapan Sape, tandha', pencak silat Cimande, pencak silat Pamor dan lain-lain.
Perihal sastra lisan di Kecamatan Bluto, Desa Aengdake merupakan desa di mana masyarakatnya masih banyak yang mengadopsi tradisi dan kebudayaan dari leluhurnya. Makanya tidak heran bila kebanyakan masyarakat Desa Aengdake sampai saat ini masih banyak yang mengadopsi paparegan para leluhurnya. (id.wikipedia,bahasa madura)

Kajiannya, sebuah kebudayaan adalah sesuatu yang akan mempengaruhi tingkat pengetahuan dan meliputi sistem ide atau gagasan yang terdapat dalam pikiran manusia, sehingga dalam kehidupan seharihari, kebudayaan itu bersifat abstrak. Sedangkan perwujudan kebudayaan adalah benda-benda yang diciptakan oleh manusia sebagai makhluk yang berbudaya, berupa perilaku dan benda-benda yang bersifat nyata, misalnya perilaku, bahasa, peralatan hidup, organisasi sosial, religi, seni, dan lain-lain.

Hakikatnya, kebudayaan itu adalah suatu cara hidup yang berkembang dan dimiliki bersama oleh sebuah kelompok orang dan 
diwariskan dari generasi ke generasi. Budaya itu sendiri terbentuk dari banyak unsur yang rumit, termasuk sistem agama dan politik, adat istiadat, bahasa, pakaian, bangunan, dan karya seni. Masing-masing kebudayaan itu digunakan oleh masyarakat Indonesia sesuai dengan penggolongan lingkungan dan pola interaksi yang dihadapi dan untuk kerangka acuan bagi identitas sesuai dengan pola interaksi dimana dia terlibat di dalamnya.

Bahasa, sebagaimana juga budaya, merupakan bagian tak terpisahkan dari diri manusia sehingga banyak orang cenderung mengaanggapnya diwariskan secara genitik. Ketika seseorang berusaha berkomunikasi dengan orang-orang yang berbeda budaya dan menyusuaikan perbedaanperbedaannya, membuktikan bahwa budaya itu dipelajari (Alisjahbana, 2008: 146).

Dinamika di atas merupakan penyebab masing-masing kebudayaan tersebut bukan hanya menjadilandasan bagi corak pranatapranata sosialnya tetapi juga mewarnai corak dari berbagai situasi-situasi sosial yang secara keseluruhan merupakan suasanasuasana kehidupan sosial yang dapat digolongkan sebagai suasana suku bangsa, suasana umum lokal, dan suasana nasional. (Sudikan, 2000:4).

Kebudayaan merupakan hasil belajar yang sangat bergantung pada pengembangan kemampuan manusia yang unik yang memanfaatkan simbol, tanda-tanda, atau isyarat yang tidak ada paksaan atau hubungan alamiah dengan halhal yang mereka pertahankan. Menurut Supalan (dalam Sudikan, 2001:114) Budaya yang dimaksud disini yaitu kebudayaan yang dibangun dan berkembang dalam sekelompok masyarakat dan pewarisnya adalah generasi yang akan datang dengan melalui suatu proses belajar dan dengan menggunakan simbol-simbol yang terwujud dalam bentuk yang terucapkan maupun tidak.

Folklor merupakan istilah umum untuk aspek material, spritual, dan verbal dari suatu kebudayaan yang ditranmisikan secara oral melalui pengamatan ataupeniruan. Folklor dapat ditemukan pada setiap masyarakat tradisional di belahan dunia manapun. Hanya bentuknya saja yang berbeda-beda. Setiap folklor memiliki ciri khas masingmasing, meakipun secara garis besar folklor mempunyai satu ciri umum, yaitu milik bersama (Koplan dkk, 2002:18).

Penggalian kearifan lokal sangat penting terhadap pembentukan karakter anak Indonesia khususnya di Sumenep Madura karena permainan anak tradisional yang ada di Sumenep memiliki makna dan kaya akan nilai-nilai karakter pembangun jiwa, sikap dan mental usia anakanak. Nilai-nilai tersebut di antaranya; (a) nilai spritual, (b) nilai karakter disiplin dan menghargai, (c) nilai etika dan moral, (d) nilai peduli sosial, (e) nilai cinta damai, toleransi dan bersahabat. Selain dari nilai-nilai tersebut permainan anak tradisional ini merupakan saran hiburan yang 
Pendas : Jurnal Ilmiah Pendidikan Dasar, ISSN Cetak : 2477-2143 ISSN Online : 2548-6950 Volume III Nomor 2, Desember 2018

dapat menjalin keakraban dan persaudaraan sesama teman (M. Ridwan, 2017:60).

Berbicara Paparegan yang meruakan bagian dari Folklor, Desa Aengdake dikenal memiliki Paparegan yang khas dan unik, paparegan merupakan salah satu peninggalan dari petuah-petuah di desa Aengdake. Sastra lisan yang masih tumbuh dan diantaranya berkembang di masyarakat Aengdake tersebut ternyata memiliki nilia-nilai filosofi tinggi diantaranya adalah nilai pendidikan, tentang etika atau moral, pendidikan agama, serta rentetan peristiwa sejarah melalui permainan, nilai-nilai kepribadian, Pembentukan budi pekerti, serta pendidikan agama ditanamkan.

Berbagai deskripsi perilaku absud orang-orang Madura terutama masyarakat Aengdake terbiasa diungkap dan ditampilkan misalnya, dalam forum-forum pertemuan komunitas intelektual sehingga kian mengukuhkan generalisasi identitas mereka. Perjalanannya, ada berupa tahapan dalam menandai kurun waktu perkembangannya, meski tahapan ini sangat relative sebagai standart baku untuk sebuah kriteria periode paling akhir belum didapat buku-buku standar yang mengurai perkembangan sastra Madura.(Tokoh masyarakat).

Penggunaan bahasa dalam sastra tulis di Desa Aengdake hanyalah sebagian saja, tradisi sastra lisan dalam bentuk sastra bertutur, serta dalam bentuk dongeng. Umumnya, isi paparegan di Desa Aengdake ini bersifat hayalan semata. Namun di dalamnya terkandung nilai-nilai pendidikan, nasihat, atau ajaran moral, etika, dan agama.

Rancangan penelitian ini bertujuan untuk memperoleh data yang lebih mendalam dan lebih valid tentang struktur paparegan yang digunakan di Desa Aengdake Kec. Bluto Kab. Sumenep. melalui penelitian ini nantinya diharapkan dapat menjadi wahana pelestarian dan pengembangan paparegan di desa terkait.

Paparegan sudah ada sejak jaman dahulu dan sudah di wariskan dari generasi ke generasi. Setiap masyarakat Madura khusus di Desa Aengdake mayoritas masih menggunakan paparegan tersebut. Tak heran, bila paparegan sampai saat ini masih tetap di gunakan oleh masyarakat Sumenep khususnya di Desa Aengdake. Paparegan di desa Aengdake ada yang terdiri dari dua baris, ada juga yang terdiri dari empat baris. Adapun batasan masalah dalam penelitian ini mengkaji pada aspek proses penggunaan struktur paparegan.

\section{B. Landasan Teori}

Kata folklore adalah kata majemuk, yang berasal dari dua kata dasar folk dan lore. Folk sama artinya dengan kata kolektif (collectivity). Folklor merupakan bagian dari tradisi yang berkembang di tengah rakyat jelata yang menggunakan bahasa sebagai media utama. Menurut Danandjaya, (dalam Sudikan, 2001:162) mendefisinikan folklor yaitu sebagian kebudayaan kolektif yang 
Pendas : Jurnal Ilmiah Pendidikan Dasar,

ISSN Cetak : 2477-2143 ISSN Online : 2548-6950

Volume III Nomor 2, Desember 2018

tersebar dan diwariskan turun menurun, secara tradisional dalam versi yang berbeda, baik dalam bentuk lisan maupun contoh yang disertai dengan gerak isyarat atau alat bantu pengingat.

$$
\text { Folklor memiliki ciri-ciri }
$$

sebagai berikut :

1. Pada dasarnya bersifat lisan dari perbuatan

2. Bersifat tradisional

3. Tersebar dalam versi yang berbeda-beda

4. Anonim

5. Mempunyai bentuk klise berupa ungkapan-ungkapan tradisional yang stereotip; dan,

6. Mempunyai fungsi atau kegunaan dalam kehidupan kelompok yang memilikinya

Folklor umumnya dituturkan, didengarkan dan dihayati secara bersama-sama pada peristiwa tertentu, dengan maksud dan tujuan tertentu pula. Peristiwa-peristiwa tersebut antara lain brkaitan dengan upacara perkawinan, upacra menanam dan menuai padi, kelahiran bayi dan upacara yang bertujuan magis. Untuk menjaga kelangsungan sastra lisan ini, warga masyarakat mewariskan secara turun menurun dari genersi ke generasi.

Folklor memiliki beberapa bentuk yaitu folklor lisan dan folklor sebagian lisan. Folklor lisan diantaranya Bahasa Rakyat, Ungkapan tradisional, pertanyaan tradisional, serta sajak dan puisi rakyat. Sedangkan folklor sebagian lisan seperti halnyakepercayaan rakyat dan permainan anak. Adapun fungsi folklor adalah menjadi pedoman, memberikan jaminan dan pengembangan ilmu pengetahuan dan filsafat dalam alam fikir modern.

Menurut Suparlan (dalam Sudikan, 2001:2-3), kebudayaan dapat didefinisikan sebagai suatu keseluruhan pengetahuan manusia sebagai makhluk sosial yang digunakan untuk memahami dan mengintepretasi lingkungan dan pengalamannya, serta sebagai pedoman bagi tingkah lakunya. Kebudayaan merupakan bagian tak terpisahkan dari manusia sehingga banyak orang cenderung menganggapnya diwariskan secara genetic. Kebudayaan terdiri dari beberapa unsur yaitu alat teknologi, sistem komonikasi, keluarga dan kekuasaan politik.

Sebagaimana ditegaskan M. Ridwan (2017:253) Sumenep dikenal dengan kota budaya dan pulau Madura memiliki berbagai budaya tradisional dan berbagai jenis wisata yang sangat beragam. Sebagaimana bentuk-bentuk folklor di atas, sastra lisan juga dapat berbentuk ungkapan tradisional, teka-teki, prosa rakyat, nyanyian rakyat, teater rakyat, arsitektur rakyat, musik rakyat, permainan rakyat.

Kebudayaan mempunyai fungsi yang sangat besar bagi manusia dan masyarakat. bermacam kekuatan yang harus dihadapimasyarakat dan anggota- anggotanya seperti kakutan alam, maupun kekuatankekuatan lainnya di dalam masyarakat itu sendiri tidak selalu baik baginya. selain itu, manusia dan masyarakat memerlukan pula 
Pendas : Jurnal Ilmiah Pendidikan Dasar,

kepuasan, baik dibidang spiritual mauun material.

Stuktur adalah hubungan antara unsur-unsur pembentuk dalam susunan keseluruhan, hubungan antara unsur-unsur tersebut berupa hubungan dramatik, logika maupun waktu, jadi dalam struktur ada satuan unsur pembentuk dan susunannya. Teori struktur membahas dua masalah yaitu masalah Etika dan Estetika. Etika membahas tentang baik buruknya tingkah laku manusia sedangkan Estetika membahas mengenai keindahan. Tugas teori struktur adalah menyelesaikan masalah etika dan estetika dimana perbahasan tentang nilai ini banyak teori yang dikemukakan oleh beberapa golongan dan mempunyai pandangan yang tidak sama terhadap nilai itu.

Objek dalam penelitian ini sifatnya budaya sehingga bukanlah hal baru bagi kita sehingga penelitian semacam ini tentu sudah pernah diteliti, bahkan ada beberapa penelitian yang hampir mirip dengan penelitian yang saya teliti.

\section{Metode Penelitian}

Keterkaitan penelitian ini diharapkan dapat menemukan sekaligus mendiskripsikan data secara menyeluruh dan utuh mengenai proses penggunaan struktur paparegan di Desa Aengdake. Untuk mendapatkan gambaran yang menyeluruh dan utuh maka pendekatan penelitian ini yang sesuai sesuai adalah menggunakan pendekatan kualitatif. Pendekatan kualitatif adalah penelitian yang menghasilkan prosedur analisis yang tidak menggunakan prosedur analisis statistik atau cara kuantifikasi lainnya (Moleong, 2009:31).

Adapun mengenai bentuk penelitian ini merupakan kasus yang dirancang sebagai suatu fenomena dengan cara mendeskripsikan variabel yang berkenaan dengan permaslahan yang diteliti, dalam penelitian ini bertujuan mendapat gambaran mendalam tentang proses penggunaan struktur dan fungsi paparegan di Desa Aengdake dengan pendekatan kualitatif, data dikumpulkan dari latar yang alami (natural setting) sebagai sumber data langsung. Penggunaan metode kualitatif dalam penelitian ini adalah untuk memahami, menafsirkan makna suatu peristiwa, tingkah laku manusia dan latar belakang alamiah secara holistic-kontekstual (Sugiono, 2010:60).

Ciri khas yang dilakukan dalam pendekatan penelitian kulaitatif ini adalah penelitian ini tidak dapat dipisahkan dari pengamatan berperan serta, namun peranan peneliti yang menentukan keseluruhan skenerionya (Moleong, 2009:104) artinya adalah peneliti harus terlibat langsung sebagai instrumen penelitian dengan memperhatikan kemampuan peneliti dalam hal bertnya, melacak, mengerti, dan memahami data yang ada.

Prakteknya, penelitian ini berlangsung selama 8 bulan. Data penelitian ini dibagi menjadi dua, 
Pendas : Jurnal Ilmiah Pendidikan Dasar,

yaitu data primer dan data skunder. Sumber data primer adalah sumber data yang langsung berkaitan dengan subyek penelitian, dalam penelitian ini peneliti menganggap masyarakat pesisir Desa Aengdake merupakan pihak yang terkait langsung dengan penelitian ini. Adapun data skunder diperoleh dari informan-inforaman lain seperti dokumen desa dan dokumendokumen pendukung yang lainnya.

Metode pengumpulan data dilakukan dengan menggunkan tiga metode yaitu: wawancara mendalam, pengamatan berperan, dan dokumentasi. Dalam penelitian ini pemeriksaan keabsahan data didasarkan pada kreteria-kretetia untuk menjamin kepercayaan data yang diperoleh melalui penelitian. Menurut Moeloeng kreteria tersebut ada empat yaitu: kredibilitas, keteralihan, Dependibilitas (kebergantungan), dan konfirmabilitas (kepastian).

\section{Hasil dan Pembahasan}

Paparegan merupakan salah satu jenis puisi lama. Oleh karennaya, sistem dan struktur paparegan masih menggunakan mode lama yang cenderung mengikat dan kaku. Kajian teorinya, pantun terdiri atas empat larik (atau empat baris bila dituliskan), bersajak ab-ab ataupun aa-aa. Pantun pada mulanya merupakan sastra lisan namun sekarang dijumpai juga pantun yang tertulis dan secara struktur paparegan terdiri dari sampiran dan isi.

Menurut Sutan (2000:13) fungsi sampiran terutama menyiapkan rima dan irama untuk mempermudah pendengar memahami isi pantun. Ini dapat dipahami karena pantun merupakan sastra lisan. Meskipun pada umumnya sampiran tak berhubungan dengan isi terkadang bentuk sampiran membayangkan isi.

Paparegan yang digunakan oleh masyarakat desa Aengdake terdiri dari beberapa bentuk sebagai berikut :

1. Karmina

Masyarakat biasa menyebut karmina sebagai paparegan (pantun) kilat karena hanya terdiri 2 baris yang bersajak a-a. Baris pertama merupakan sampiran dan baris kedua merupakan isi. jenis paparegan ini merupakan jenis paparegan yang sering diigunakan oleh masyarakat Desa Aengdake. Contoh paparegan dalam bentuk karmina ditujukan pada wawancaraberikut :

Peneliti : "Apakah Bapak

banyak tahu tentang paparegan

yang sering digunakan oleh masyarakat Desa Aengdake?"

Haris : "Ya, karena paparegan disini sangat sigemari.

peneliti : "contohnya pak ?"

Haris : Sampan parao, yang artinya Tabu'lapar tadha'tao"

Peneliti : "Ada yang Bapak ketahui lagi yang lain" 
Pendas : Jurnal Ilmiah Pendidikan Dasar,

\begin{tabular}{|c|c|}
\hline Haris & $\begin{array}{l}\text { : ada, "Pangkor nyang- } \\
\text { kornyangan, artinya } \\
\text { Reng dhapor } \\
\text { nyang- } \\
\text { kennyangan". }\end{array}$ \\
\hline Haris & $\begin{array}{c}\text { : "Sampang Aengdake } \\
\text { arrtinya gempang } \\
\text { mon lamare". }\end{array}$ \\
\hline Haris & $\begin{array}{l}\text { : "Kaju seccang kaju } \\
\text { mondhu, artinya } \\
\text { Mata peccang la } \\
\text { katondhu". }\end{array}$ \\
\hline Haris & $\begin{array}{l}\text { : "Teter kokina badha } \\
\text { diya, artinya Ja' } \\
\text { kobater kopina la }\end{array}$ \\
\hline
\end{tabular}

sadiya".

Kalimat yang dicetak tebal pada data wawancara di atas merupakan sampiran paparegan, sedangkan yang dicetak miring merupakan isi dari paparegan. Paparegan yang disampaikan oleh Haris diatas termasuk paparegan karmina, sebab paparegan tersebut hanya terdiri dua baris bersajak a-a. Baris pertama merupakan sampiran dan baris kedua merupakan isi.

2. Talibun

Paparegan jenis talibun merupakan jenis paparegan yang panjang dengan jumlah baris yang sangat melimpah. umumya banyak baris dalam talibun merukan kelipan tadi empat dengan sistem tambah (empat baris, enam baris, delapan, bahkan dua puluh baris dan selalu genap) dengan Sajak $A B-A B, \quad A B C D-A B C D$, dan seterusnya. Berikut ini adalah contoh paparegan dalam bentuk talibun :
Peneliti : bagaimana contoh talibun pak?

Abd Rafi' : "Kan akowak

epakaje, ma' ta' rengsa se

nyare"

Peneliti : "Maksudnya

pak ?"

Abd Rafi' : "Reng ta' kowat ja' akarja, ma' ta' sossa budhi are"

Analisisnya, Paparegan

diatas termasuk paparegan jenis talibun, sebab paparegan yang ditulis tebal dan miring diatas semuanya terdiri dari empat baris. Hal tersebut ditunjukkan dengan dua baris sampiran berupa ungkapan Kan akowak epakaje, ma' ta' rengsa se nyare" dan dua baris isi yang berupa ungkapan "Reng ta' kowat ja' akarja, ma' ta' sossa budhi are".

3. Saloka

Paparegan Saloka adalah paparegan yang terdiri atas beberapa bait sambungmenyambung jika dilisankan, bersahut-sahutan. Masyarakat desa Aengdake biasa menyebutnya dengan paparegan berkait. Paparegan jenis Saloka ini kerapkali kita jumpai tampa dalam kehidupan sehari-hari dengan pengguna yang merata pada setiap elemen masyarakat. Paparegan Saloka dapat ditemukan pada tuturan berikut :

Konteks : "Wawancara peneliti dengan Bapak Subahra selaku petani Desa Aengdake". 
Pendas : Jurnal Ilmiah Pendidikan Dasar,

Subahra : "Ngala' lalang

ka Panglegur, ngala' trata

samperanna"

Peneliti : "Artinya apa

pak ?"

Subahra : "Ta' alanglang

dika lebur, kor ta' loppa

Pangeranna"

Tuturan yang disebutkan

oleh Bapak Subahra diatas merupakan paparegan Saloka, hal ini dibuktikan dengan kalimat yang diulang dalam paparegan tersebut yaitu "ngala".

Sekolah Dasar sebagai institusi pendidikan harus mempersiapkan strategi untuk internalisasi nilai-nilai budaya yang berbasis lokalitas seperti paparengan. Dimensi karmina, talibun dan Saloka dalam paparegan adalah warisan kebudayaan adiluhung dari nenek moyang.

$\begin{array}{ccc}\text { Siswa } & \begin{array}{c}\text { sekolah } \\ \text { kepada }\end{array} \\ \text { berdasar } & \text { prinsip }\end{array}$
pendidikan berbasis kearifan lokal, pendidikan karakter, moral dan budi pikerti, implementasinya harus selaras dengan nilai-nilai lokalitas budaya yang ada. Maka menjadi penting, nilai-nilai luhur dalam budaya paparegan Madura dipelajari di Sekolah Dasar khususnya di wilayah Kabupaten Sumenep.

\section{E. Kesimpulan}

Paparegan sudah ada sejak jaman dahulu dan sudah diwariskan dari generasi ke generasi. Setiap masyarakat Madura khusus di Desa Aengdake mayoritas masih menggunakan paparegan tersebut. Paparegan sering digunakan oleh masyarakat setempat untuk mencari hiburan dan sebagai bentuk ketaatan pada keyakinan yang mereka peroleh dari nenek moyang. Sebagai komitmen mengurangi ketergantungan generasi saat ini (siswa SD), maka penting nilai-nilai lokalitas dalam budaya paparegan juga dipelajari oleh mereka sebagai penerus estafet kebudayaan untuk masa yang akan datang.

Paparegan yang ada di desa Aengdake, memiliki beberapa bentuk yaitu :

1. Karmina

Karmina disebut juga paparegan (pantun) kilat karena hanya terdiri 2 baris yang bersajak a-a. Baris pertama merupakan sampiran dan baris kedua merupakan isi. Contohnya seperti Sampan parao, yang artinya Tabu'lapar tadha'tao"

2. Talibun

Talibun merupakan jenis paparegan yang panjang dengan jumlah baris yang sangat melimpah. umumya banyak baris dalam talibun merukan kelipan tadi empat dengan sistem tambah dengan Sajak AB-AB, ABCD$A B C D$, dan seterusnya. contohnya seperti paparegan "Kan akowak epakaje, ma' ta' rengsa se nyare" yang mempunyai arti "Reng ta' kowat ja' akarja, ma' ta' sossa budhi are"

3. Saloka

Saloka adalah paparegan yang terdiri atas beberapa bait sambung-menyambung jika dilisankan, bersahut-sahutan. 
Contohnya seperti paparegan

'Ngala' lalang ka Panglegur, ngala'

trata samperanna" dengan

mengulang kata Ngala'.

\section{DAFTAR PUSTAKA}

Alisjahbana, Takdir S. (2008). Seni dan Sastra di Tengah-Tengah Pergolongan Masyarakar dan Kebudayaan, Jakarta: Dian Rakyat.

Koplan, David dkk. (2002). Teori Budaya, Yogyakarta: Pustaka Pelajar.

Moleong, Lexy. (2009). Metode Penelitian Kualitatif, Bandung: Remaja Rosdakarya.

Ridwan, M. and Wahdian, A., (2017). Structure, Function And Value The Tradition Of Oral Literature In Sumenep Madura. ISLLAC: Journal of Intensive Studies on Language, Literature, Art, and Culture, 1(1), pp.252-273.

Ridwan, M., (2017). Tradisi Nyanyian Anak terhadap Pembentukan Karakter Anak Usia Sekolah Dasar. Sekolah Dasar: Kajian Teori dan Praktik Pendidikan, 26(1), pp.49-61.

Sudikan, Setya Tuwana. (2001). Metode Penelitian Kebudayaan, Surabaya: Citra Wacana.

Sugiyono. (2010). Metode Penelitian Kuantitatif dan R\&D, Bandung: Alfabeta Veeger.

Sukur, Notoasmoro, Abd. (2008). Pramasastra Madura Pelopor Pendidikan STKIP PGRI Sumenep. 